\section{Narrativa de Abilio Estévez: hacia una estética de la sujeción-expolición.}

Abilio Estévez Narrative: Towards an Aesthetics of the Subjetion-Commoratio.

\section{Fernanda Bustamante}

Universidad de Barcelona, España

fernandabustamante@gmail.com

Resumen - El objetivo del artículo es realizar una aproximación crítica a la narrativa del escritor cubano en el exilio, Abilio Estévez, a partir de la identificación y problematización de sus procedimientos estilísticos retóricos (campos semánticos, metáforas, alegorías) y estructurales (intertextualidad, polifonía, lenguaje acotacional, paratextos y lo metaliterario). Observo cómo su proyecto literario ha ido articulando una estética de la sujeción-expolición en la que Cuba (La Habana) es la materia escritural y el narrador totalizador su soporte.

Palabras clave: literatura cubana del exilio, sujeción, expolición, narrador totalizador, intertextualidad, polifonía, metaliterario.

Abstract • This article is intended to make a critical approach to the narrative of Abilio Estévez, an exiled Cuban writer. To that effect, I will begin with the identification and questioning of his aesthetic procedures: in terms of rhetoric (semantic field, metaphor, allegory) and structure (intertextuality, polyphony, marginal notes, paratext, metaliterary). It is possible to observe how his literary project is able to articulate a subjetion-commoratio aesthetics. In this context, Cuba (La Habana) is presented as the writer's material and the "totalizing narrator" as its canvas.

Keywords: Cuban Literature of the Exile, Subjetion, Commoratio, Totalizing Narrator, Intertextuality, Polyphony, Metaliterary.
Los elementos constitutivos de la literatura cubana contemporánea (más bien per se) han hecho que lo propio de ésta sea la tensión. Dialogar con la Cuba literaria implica vagar entre antítesis discursivas liberadoras y opresoras a la vez. Un adentro y un afuera, un paraíso y un infierno, un actuar y un esperar, un expulsar y un atraer, un sí y un no, una nada y un todo que se entrecruzan, superponen y vinculan indiscriminadamente, enmarcando las creaciones (pasadas, presentes e indudablemente, futuras). A esto se le suma el determinismo histórico y geográfico, y en consecuencia, político y social de la isla que también se configura como condicionante ideológico, tanto de sus agentes como de sus producciones culturales, donde la tensión de fondo está entre la búsqueda de "lo cubano" o el rechazo de éste.

Agobio y seducción, así como exceso y carencia, pasan a ser apreciaciones estéticas, extrañamente, compatibles a la hora de enfrentarse a un texto literario cubano reciente, ubicando de esta manera a la tensión en el eje de la recepción. Particularmente la narrativa de los últimos años ha sido adjetivada por la crítica como pesimista, del desencanto, de la marginalidad, de la incertidumbre y del exilio, sintetizándose en una prosa de la revolución truncada, del dolor, y de la supervivencia (¿o su inverso?).

Pareciera que la literatura de la isla estuviera empeñada en hacer desaparecer la noción occidental de la historia, dándonos a entender que Cuba presenta una constante cultural dominante transgresora a todo momento histórico y generación literaria, siendo ésta la tensión identitaria del sujeto y de la nación isleña.

Abilio Estévez, (1954), forma parte de los narradores contemporáneos de la isla, reconocidos por la crítica nacional e internacional ${ }^{1}$. Sus obras publicadas fuera de Cuba, que se inscriben en diversos géneros (relatos, cuentos, teatro y novela), dejan entrever su cometido literario, que se aleja de lo político-propagandístico, sin desprenderse de su gentilicio: cubano ${ }^{2}$. El objetivo del presente artículo es realizar una primera aproximación a la narrativa de Estévez a partir de la identificación de sus procedimientos estilísticos, y tratamiento temático, tomando como referentes sus novelas Tuyo es el reino (1997), Los palacios distantes (2002), El navegante dormido (2008), y su obra "mixta" Inventario secreto de la Habana (2004). Para ello planteo como hipótesis que Abilio Estévez, presenta la tensión cubana articulando una estética de la sujeción-expolición: su proyecto literario es incapaz de desprenderse de Cuba y del "todo narrativo", envolviendo sus relatos en una retórica de la redundancia y saturación.

Su obra dramática La verdadera culpa de Juan Clemente Zenea obtuvo el Premio José Antonio UNEACC en 1987; su poemario Manual de las tentaciones el Premio Luís Cernuda en 1987; por su obra dramática L 1999 y en Francia el Pre Molina en 1994; su novela Tuyo es el reino (1997) el Premio de la Crítica Cuban especializada por la puesta en escena de la pieza Un sueño feliz y el Premio "Santiago Pita" al mejor texto teatral presentado en el Festival de Teatro de La Habana, por La verdadera culpa de Juan Clemente Zenee; y en 1989 su libro Manual de las tentaciones obtuvo el Premio "Luis Cernuda", de España, y el Premio de la Crítica Cubana.

Sus obras publicadas son: El navegante dormido (novela, 2008); Ceremonia para actores desesperados (dramaturgia, 2004); Inventario secreto de La Habana (género mixto, 2004); Los palacios distantes (novela 2002); Manual de tentaciones (prosa poética, 1999); El horizonte y otros regresos (cuentos y relatos, 1998); Tuyo es el reino (novela, 1997); La noche y Un sueño feliz (teatro, 1997); Muerte y transfiguración (poema, 1995); Santa Cecilia (teatro, 1995); Perla marina (teatro, 1993); Yo tuve un sueño feliz (teatro, 1989); Manual de las tentaciones (poemario, 1989); La verdadera culpa de Juan Clemente Zenea (teatro, 1987); Juego con Gloria (cuentos, 1987). 
Las obras de Estévez dialogan entre sí. Si bien no corresponden al mismo género, ni tienen dependencia o continuidad temática, dejan entrever el surgimiento y desarrollo de su propuesta artística, articulada bajo una estética postmoderna, en la que la protagonista y eje de las narraciones es la isla, y el soporte es el narrador totalizador. Paradójicamente, sus fisuras narrativas emergen de ambos elementos, ya que al estar sujeto (esclavizado) a ellos, tiende a construir una narrativa de la expolición, en la que, independiente de los modos (estructurales o retóricos) que utilice, lo dicho y lo silenciado (que en realidad, no es silenciado), redundan en una misma idea.

\section{LAS OBRAS: SUS PUNTOS SÍMILES Y DISÍMILES}

Todas sus novelas se sitúan en Cuba, en diferentes contextos y períodos: Tuyo es el reino en 1959 con la entrada de los rebeldes a la Habana, Los palacios distantes en la víspera del nuevo milenio y El navegante dormido en 1977, con la llegada de un ciclón a la isla. La temática de la memoria y el olvido es transversal a todas sus obras. En cada una de ellas se narra un relato fundacional (el de la Isla, del teatro, o del bungalow) que al vincularse con los argumentos respectivos conducen a una reflexión en torno al paso del tiempo, y a la existencia de la historia: ¿se asume o se niega el pasado?, ¿ha formado parte Cuba de la historia, o es la historia de Cuba inmóvil y eterna a la vez? La construcción y caracterización de los personajes también muestran un patrón: desvalidos, insatisfechos, carentes. Fundadores, visionarios, desaparecidos, se desplazan por sus obras, se mimetizan, se difuminan. La clase social a la que pertenecen es una sola, el sentimiento que transmiten, también es uno solo. Estévez muestra un escenario en donde la clase media, en realidad baja, es "la" clase, y donde la desolación y desarraigo son "los" estados anímicos existentes.

Por otra parte, la presencia de la revolución castrista también emerge en sus novelas. Sin tener un rol protagónico, más bien silenciado, en todas ellas se narran episodios relativos a ella (la huída de Batista en Tuyo es el reino; nombrar a Victorio por haber nacido el día en que los rebeldes entraron en la capital, en Los palacios distantes; y la discusión entre Olivero y Elisa sobre la supuesta justicia social que implicó la revolución, en El navegante dormido, etc.). Este espacio que se le ha entregado, alejado de un tono contestatariosubversivo, deja entrever una ideología del "no", del "anti" régimen, que se inserta más bien, en el paradigma de lo simbólico-reflexivo de las respectivas novelas.

Cabe señalar, que la segunda novela, Los palacios distantes, se diferencia en algunos aspectos. Presenta el desarrollo del argumento en forma lineal y estable, a diferencia de las otras dos que son fragmentadas tanto en el tiempo como en el espacio. Su ritmo es más pausado, tal vez debido a poseer sólo tres personajes centrales que se desenvuelven en un continuo, y el tono de la enunciación es menos violento y punzante, de mayor resignación. Sin embargo, las mayores diferencias se encuentran en el narrador y en lo metaliterario. $\mathrm{Si}$ bien las tres se configuran a partir de un narrador omnisciente, poseedor del "todo narrativo", sus dos novelas límites se sustentan en un narrador que se materializa en un personaje (Sebastián en Tuyo es el reino, y Valeria en El navegante dormido) y en consecuencia conduce a una reflexión explícita en torno al acto de escribir, mientras que en la segunda, el narrador se limita, aparentemente, a narrar.

El caso de Inventario secreto de la Habana es diferente. Es un texto compuesto por dos ejes que a nivel temático e ideológico, se intercalan, oponen y complementan. Por una parte, escritos-reflexiones de Abilio Estévez sobre la Habana, en los que bajo un "yo" narrativo (que oscila entre lo testimonial y lo ficcional) hace un recorrido por sus calles, monumentos, figuras emblemáticas, destacando lo anónimo y lo comúnmente silenciado de la ciudad. Por otra, una selección de textos de diferentes autorías y épocas que tienen a la Habana como material escritural. Éstos, se encuentran ordenados desde 1800 hasta el 2002, pasando por Alejandro de Humboldt, Anaís Nin, Federico García Lorca, Juan Ramón Jiménez, Alejo Carpentier, Eliseo Diego, Virgilio Piñera, María Zambrano, Graham Greene, Ernest Hemingway, entre varios otros. De esta manera, la obra titulada "Inventario" se estructura como una recopilación bibliográfica, como un poli discurso diacrónico de la Habana, que también nos conduce a la idea del tiempo, de la reescritura de la memoria, pero principalmente del imaginario ${ }^{3}$ que se ha construido alrededor de la ciudad y la isla.

En una primera instancia, los textos de Abilio Estévez parecieran enmarcarse en una estructura narrativa en la que predomina la intertextualidad ${ }^{4}$ y polifonía. En todas sus obras, se establecen relaciones, literales (principalmente en Inventario secreto de la Habana y Tuyo es el reino) o alusivas (que son las que predominan en Los palacios distantes y El navegante dormido) con otros textos y autores, los que son intercalados arbitrariamente entre las narraciones; o citados por los personajes, o el narrador, quienes se apropian de esos discursos y les dan voz. La Cuba literaria de Estévez como texto y "performatividad" que se constituye al ser enunciada y que se enuncia bajo los dispositivos del montaje, y del control predefinido del narrador.

\section{PROCEDIMIENTOS ESTILÍSTICOS CONSTITUTIVOS: CUNA DE SUS FISURAS}

\section{NARRATIVAS}

A continuación pretendo realizar un recorrido por las cuatro obras con la intención de identificar los procedimientos estilísticos constitutivos de la propuesta literaria de Abilio Estévez. Qué es lo dicho y cómo ha sido dicho, conforman el pilar de mi problematización ya que me permitirán dar cuenta de la sujeción y expolición narrativa en la que han caído sus obras, las cuales, bajo una potencializada significación léxica y estructural, tienden a un agobio textual, configurando una retórica de la saturación, de lo evidente, de lo sobrante.

El primer elemento constitutivo y sujecivo de su obra es Cuba, la cual, en cada página es flagelada y desechada a la vez. Su obra se sustenta, temática e ideológicamente en la idea, persistente, de que la fatalidad y desamparo son la condición fundante de la isla, por lo que desprendo un determinismo al que Estévez, en lugar de hacerle resistencia, acoge y se subyuga a él.

Cuba y La Habana son representadas como espacios colmados de sentido. En este punto los procedimientos retóricos utilizados por el autor cobran relevancia. Todas las connotaciones y adjetivaciones de la isla y su capital son peyorativas y se materializan en

Entenderé por "imaginario", a los "esquemas de representaciones que permiten construir la verdad, entendiendo que dicha creación implica siempre un recorte de lo real” (Sepúlveda: 73), por lo que no funcionan como reflejo de la realidad misma, sino como una interpretación de ella.

Por "intertextualida" me remitié a Julia Kristeva, quien a partir de los postulados de Baitin indica "[ ] ] palabra (el texto) es un cruce de palabras (de textos) en que se lee al menos otra palabra (texto) [...] Es Bajitin el primero en introducir en la teoría literaria: todo texto se construye como mosaico de citas, todo texto es absorción y transformación de otro texto" (Kristeva, 1981: 190). 
diferentes campos semánticos que gobiernan los relatos, envolviéndolos a todos en una misma atmósfera de lo desfavorable, el hastío y la desidia.

Cuba como país del cual se tiene aversión y odio: "Mierda de tierra, mierda de mar. Nadie nunca ha querido estar aquí" (2004: 45); "esta mierda en forma de cocodrilo donde vivimos" (2008: 117). Cuba y La Habana como espacios que infunden terror: "esto no es una isla [...] sino un monstruo" (1998: 42); "terrorífica ciudad [...] infierno que habitamos" (2002. 99); "ciudad maliciosa [que] posee su propia perversidad" (2004: 308); "[ciudad donde todo era amenazante" (2008: 35); "[lugar donde] siempre estamos en peligro" (2008: 48).

Por otra parte, se envuelve al país en el agobio de la inercia ${ }^{5}$, de la inactividad y monotonía que consume a los personajes: "[el Tío Rolo] experimenta el alivio de tener algo que hacer" (1998, 47); "Y así vivíamos [...] En aquel saber estar sin hacer nada" (2004

95); “ ¿Hay algo que hacer? Me parece que vivo siempre en la misma escena” (2008: 323).

Irónicamente, la única acción que fractura esta nadaactividad ${ }^{6}$ es esperar. Este es el mayor acto del habanero, y a la vez su mayor enfermedad: "La Habana se fundó para esperar [...] ¿Qué? Todo. Nada. Cualquier cosa. La verdadera ocupación es esperar” (2004: 73-4); "En aquella isla las cosas siempre tenían el toque supremo de la soñolencia y la inacción. Nada que hacer, salvo esperar [...] Esperar era una hacer pasivo; era, precisamente, no hacer nada" (2008: 317).

Estas imágenes de Cuba explican la crítica sensación de extrañeza que los sujetos encarnan, la tensión de vivir bajo la premisa de estar "fuera de lugar", algo así como un desapego pre-natal": "La ciudad se vuelve remota, ajena, incomprensible y hostil" (2002 46-7); "Victorio experimenta la sensación de que esa ciudad no es la suya. La Habana se convierte en una ciudad extraña, malévola, reticente, remota [...] se ha sentido ajeno" (2002: 124); "Valeria nació en La Habana y nada podría cambiar esa verdad. Nueva York, en cambio, será su nueva ciudad [...] ¿será preciso aclarar que La Habana nunca le habrá pertenecido? (2008: 91).

Es en Inventario secreto de La Habana, texto estructurado por un "yo" seudo ficcional, seudo autobiográfico ${ }^{8}$, donde el tópico del desarraigo toma mayor protagonismo: "La Habana siempre estuvo lejos. ¿ O será mejor corregir la expresión y decir que fui yo quien siempre permaneció lejos de La Habana, que mi ciudad no era mi ciudad? (2004

Particularmente en sus novelas Tuyo es el reino y Los palacios distantes, sería interesante profundizar en la figura de las estatuas y los muñecos, relacionar su condición de lo estático e inerte como símbolo de lo propio de sujeto cubano,

Virgilio Piñera en La vida tal cual indica a la "nada" como el principal rasgo de Cuba: "El sentimiento de la Nada por exceso es menos nocivo que el sentimiento de la Nada por defecto [...] Pero esa Nada surgida de ella misma, tan física como el nadasol que calentaba a nuestro pueblo de ese entonces, como las nadacasas, el nadaruido, la nadahistoria [...] a esto se llama el 'pasivo' de la Nada, y al cual no corresponde 'activo' alguno" (1990: 23). Iremo

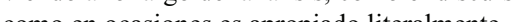
Merin

hablaba de Cuba como su patria "prenatal", vínculo con Cuba, que todos los personajes de Abilio Estévez, irónicamente desconocen.

Inscribo esta obra entre lo ficcional y lo autobiográfico, ya que si bien hay claras evidencias textuales de que el narrador- personaje es el autor Abilio Estévez, hay instancias en que este relato rompe con esta relación. En El pacto autobiográfico Lejeune define la autobiografía como un "relato retrospectivo en prosa que un persona real hace de su propia existencia, poniendo énfasis en su vida individual y, en particular, en la historia de su personalidad [...] para que haya autobiografía es necesario que coincidan la identidad del autor con la del narrador y la del personaje" (1991: 48).
87); "La Habana fue para mí un espacio distante, un territorio que de algún modo no me pertenecía” $(2004,88)$; “¿Qué haces cuando de pronto no entiendes por qué te hallas en una ciudad que no es la tuya?” (2004, 293), “y como ya he dicho, el sentimiento de lejanía no resultaba nuevo para mí” $(2004,295)$.

Este aspecto de la no-pertenencia es fortalecido a través de la caracterización de personajes que desean abandonar la isla y que la abandonan. Así como también, en cada una de los relatos en los que se alude a un Norte al que se quiere pertenecer ${ }^{10}$. En Tuyo es el reino Sebastián planifica la huida por el mar, en El navegante dormido Valeria abandonó Cuba para establecerse en Estados Unidos y Jafet desapareció tras tomar una balsa rumbo al norte; y en Inventario secreto de La Habana, el narrador-personaje declara vivir su diáspora en Barcelona.

Sin embargo, estas atribuciones que se le dan a la isla, son aún más reforzadas en la narrativa del autor. Estévez presenta un nuevo tópico: el estado apocalíptico y desventurado de Cuba, el cual se sostiene en un "siempre": "En Cuba el Apocalipsis no sorprende: ha sido siempre un suceso cotidiano" (1998: 87); “Los tiempos están malos [...] sí malos, malísimos, ¿tendrán la bondad de decirme cuándo han estado buenos? (1998: 140); "la isla fue la misma gobernara quien gobernara" (1998: 292);

En qué porquería de país hemos vivido? ¿cuándo esta puñetera isla ha sido feliz? Paraíso ninguno, ni antes ni ahora [...] Este horror que estamos sufriendo es el final de un camino que empezó en 1902, tal vez antes, en 1895 (2008: 345).

El mal de Cuba es intrínseco y eterno. Puede estar en el recuerdo, se puede estar vivenciando en un ahora, e incluso se puede presagiar ${ }^{11}$. Es una constante que trasciende todo momento histórico y que está inscrita en todo sujeto cubano. Esta martirizante concepción de La Habana como espacio donde el Apocalipsis se prolonga infinitamente es la que predomina en las obras de Abilio Estévez y es el tópico del cual se desprenden, o al cual se encauzan, las principales temáticas de su poética narrativa.

Virgilio Piñera en La vida tal cual indica "Francamente, sigo considerando La Habana como un sepulcro. Un vasto sepulcro dividido a su vez en sepulcros más pequeños” (1990:

He subrayado ciertas palabras y enunciados con la intención de indicar como el autor tiende a articular sus ideas bajo la reiteración de lexicos y/o sinonimia, siendo esto el primer rasgo de su retórica "expolitiva". Ahora bien, hay ocasiones en que ésta se presenta de forma más evidente como por ejemplo, las siguientes citas de Inventario secreto de La Habana, en las que el párrafo cambia únicanente en unas palabras: "En e pequeño atlas de nuestra geografía familiar, La Habana era aquel paraje no sólo lejano, sino además extraño, ajeno, incomprensible, o lo que es lo mismo: peligroso" (2004: 93); “En el pequeño atlas de nuestra geografía familiar La Habana era aquel paraje no sólo lejano, sino además extraño, ajeno, incomprensible, en el que estábamos y no estábamos" (2004: 135).

- También se vislumbra en sus obras, aunque con menor exacerbación, el tópico del Norte como "tierra prode partir todos hacia Estodos Unidos, nuestra versión de la Tiera Prol norte?" (2004:60) "La perenta pase por Nueva York, a diferencia de la que pasea por La Habana, se siente como un ser humato, no con un fantasma 'salir de La Habana y llegar a Nueva York [ . ] es pasar de un estado de invisibilidad a [... materialidad" (2008: 290);etc.

Esta última idea es plasmada en "visionarios" como la Condesa Descalza en Tuyo es el reino ("Este aguacero no es más que el inicio, el fin está cerca, pronto muy pronto, [...] caerá la desgracia sobre la isla” (102)); el mismo narrador, como en Los palacios distantes ("Quizás [...] se anuncie la definitiva desaparición de La Habana en los mapas del mundo" (32). 
25). Esta concepción (y esta voz) se manifiestan explícitamente en las obras en cuestión ya que se muestra a la Cuba eternamente moribunda como depósito de cadáveres, "¿Se han fijado en la Isla?, inmenso cementerio sin tumbas" (1998: 237). Más bien, como un cadáver en sí misma: "La Habana era un sepulcro" (2008: 108).

A partir de esta idea, y continuando con esta identificación de sus procedimientos retóricos, es importante destacar, por una parte, cómo estos campos semánticos se acompañan de metáforas y alegorías recurrentes en sus obras; y por otra, cómo su obra no permite que éstas signifiquen por sí solas, cayendo, a causa del narrador totalizador, en un simplismo narrativo.

Como todo texto cuya materia literaria es Cuba, y cuyo escritor es de procedencia cubana ${ }^{12}$, la condición insular no puede estar ausente. "La maldita circunstancia del agua por todas partes"13 de Piñera recorre también todas sus obras, bajo ese mismo tono de condena, de rechazo y hastío. La condición geográfica que los transforma en seres aislados y recluidos. La agobiante omnipresencia de mar y del agua que hace de éstos su principal adversario. En primer lugar, ser isleño implica configurarse como un sujeto enclaustrado. La delimitación que para algunos es protección, para otros es sinónimo de no acceso a la otredad, de libertad coartada, siendo precisamente con este paradigma con el que se identifican los personajes de Estévez: "bastante desgracia y bastante encierro significa vivir en una isla" (1998: 169); "la isla simboliza ella misma, el gran encierro, el mar como reclusión y enfermedad" (2002: 80)

Por otra parte, y como complemento de la idea anterior, el estar desprendido de la masa continental implica inestabilidad, "nada hay firme en una isla" (2004: 19). Inestabilidad geográfica que pareciera repercutir en las conductas de los isleños. El autor acude a una analogía entre las embarcaciones y las islas, para materializar: el estado de atemporalidad en el que se desenvuelven, "(las islas no son países sino barcos varados para siempre -y el tiempo, ay, no pasa en barcos varados para siempre)" (1998: 154); también la fragilidad que genera el carecer de rumbo fijo, "vivir en una isla tenía algo de barco a la deriva" (2004 49); y a su vez, la percepción de la continentalidad como redención, "lo feliz que se ha sentido [Vicenta de Paul] de pisar tierra firme [...] ha experimentado la excitación de quien abandona una balsa [...] la sensación gozosa de quien da un salto salvador" (2008: 191). ${ }^{14}$

La revisión crítica, realizada anteriormente, ha permitido identificar ciertos patrones escriturales del autor que lo han llevado a una estética expolitiva. Las imágenes se construyen a partir de una repetición léxica y simbólica que trasciende todas las obras. Para continua esta problematización de su propuesta literaria, identificaré cómo la sujeción se manifiesta, pero esta vez bajo una segunda acepción: como tendencia a anticipar la información y/o aclarar a cabalidad las interrogantes (o vacíos) que los textos van dejando. Para ello es necesario vincular sus procedimientos retóricos con los estructurales, ya que es en la figura del narrador donde, principalmente, se concretizan sus fisuras.

En su primera novela, Tuyo es el reino, que reúne la mayor cantidad de planteamientos temáticos y estéticos, cabe destacar la caracterización (o montaje) que Estévez hace de la finca La Isla. En una primera instancia pareciera que el autor, bajo la idea de círculos

Acentúo en la idea de procedencia, por sobre la afirmación que implica decir "ser cubano", especialmente debido al fuerte desarraigo planteado por gran parte de ellos.

Primer verso del poema La isla en peso de Virgilio Piñera.

14 En varias de sus obras, el autor remite el éxodo de los balseros cubanos de 1994 cuando Fidel Castro anunció el retiro de los guardas fronterizos de las costas cubanas y la autorización de dejar el país a todo ciudadano que así lo quisiese. Narra- reflexiona particularmente en torno al museo en donde se exhiben fotos de todos aquellos cubanos que no llegaron a su destino, los desaparecidos en el mar. concéntricos (Cuba - La Habana - finca La Isla) presentara el argumento, focalizando finalmente la trama en una determinado número de personajes particulares, comunes y cotidianos. Sin embargo, en la medida que avanza la narración, vemos cómo La Isla se constituye en lo que Fredric Jameson denomina alegoría de la nación, en una alegoría del estado sociopolítico de la Cuba de 1959.

All third-world texts are necessarily, I want to argue, allegorical, and in a very specific way: they are to be read as what I will call national allegories [...] even those which are seemingly they are to be read whe semingly private and invested with a properly libidinal dy nanic- necessanly project a political dimension in the form of natinal allegory: the story of the private individual destiny is always an allegory of the embattled situation of the public third-world culture and society $(1986: 69)^{15}$.

Tanto La Isla, en su estado de incertidumbre y amenaza, como los personajes vienen a representar o caracterizar Cuba y su pueblo. Bajo un contexto histórico determinado se logra la equivalencia entre un uno (la finca) y un otro (el país). Sin embargo, este logro narrativo, tanto a nivel retórico como simbólico, no logra trascender esta novela. En la segunda, Los palacios distantes, a primera vista es posible identificar otra alegoría, esta vez entre La Habana y el teatro que antiguamente era llamado Pequeño Liceo de La Habana. Si la Cuba literaria de Estévez es un cadáver es, por tanto, una ruina. Ha vivenciado y personificado la decadencia y la destrucción. Su estado y su condición es la de un residuo, un desecho, "una pieza del museo de - las - cosas - inservibles" (2002: 239). En esta obra, el campo semántico que prevalece es el de Cuba como ruinas. De hecho Fucio declara que son precisamente éstas el motor y sustento de la ciudad: "Una vez que se accede a las ruinas, resulta inevitable suponer que se ha entrado en el corazón mismo de La Habana" (2002: 96). Toda la narraciónque, en este caso, es particularmente descriptiva, sustentada en el deambular de Victorio por el lado "b" de la ciudad (que en realidad es su verdadera y única cara) se envuelve en la idea de derrumbe, indigencia, suciedad, pestilencia: "a la ciudad se la siente derrotada, desecho" $(2002,137)$. Y el teatro se presenta como símbolo y consecuencia de esa circunstancia.

Sin embargo, esta construcción alegórica se fractura. Deja de connotar algo aparte de sí misma cuando su significación se hace explícita en la voz de los personajes quienes hacen el símil entre ambos espacios: "Ha llegado a pensar que existen dos sitios diversos que son, al propio tiempo, el mismo e idéntico: La Habana y las ruinas del teatro. [...] La Habana deriva de los restos de este teatro" (2002: 95). Es precisamente en este momento cuando el procedimiento de la alegoría pierde su poder estético e ideológico. Y es esto lo que produce en los lectores, la sensación de estar sometidos a un texto cerrado, en donde nada es sugerido.

Completo esta apreciación centrándome en la problematización que Estévez hace en torno a la memoria y el tiempo. El eterno estado apocalíptico convive con la constante idea de un antes y un después, idea que a la hora de enfrentar a la memoria entra en tensión, se difumina y complejiza. He seleccionado tres citas (de las múltiples existentes), una de cada novela, con la intención de observar el recorrido argumentativo, de dar cuenta cómo "Sostengo que todos los textos [literarios] del Tercer Mundo son necesariamente alegóricos, y en una manera muy
específica: ellos deben ser lé́dos de acuerdo a lo que yo denomino alegorías nacionales [...]. Incluso aquellos texto investidos de una dinámica aparentemente privada o libidinosa- necesariamente proyectan una dimensión política en la forma de alegoría nacional: la historia del destino privado individual es siempre una alegoría de la situación conflictiva de la cultura y de la sociedad pública del Tercer Mundo" [Traducción y cursivas de la autora] 
una disyuntiva inicialmente presentada va siendo resuelta literalmente, llenando aquellos "aparentes" vacíos.

La primera cita opera como interrogante que expone el tema en cuestión: "Todo tiempo pasado fue mejor [...] ¿de qué tiempo pasado estoy hablando?, ¿cómo puedo decir que e pasado fue mejor si no recuerdo, si no sé de qué pasado estoy hablando?” (1998: 225). La siguiente funciona como primera instancia resolutiva: "La Habana carece de Historia [...] los más viejos inventan otra historia, mentirosa, como debe ser [...] entre La-Habana-queno-existe y La-Habana-paraíso-perdido" (2002: 219). De aquí se desprenden dos grandes tópicos que son lo fantasmagórico de la Habana, y la necesidad de moldear un referente que sea capaz de explicar y justificar la identidad y carácter de la ciudad (el país), es decir la construcción de un mito. Pero las obras se encargan de eliminar estas deducciones y aseverarlas textualmente: "Nunca sabremos si todo tiempo pasado fue verdaderamente mejor, o así nos lo parece porque es tiempo leído, no vivido; tiempo descifrado en las páginas de autores que lo han desmitificado y vuelto a mitificar para nosotros" (2004: 73).

Los dos ejemplos anteriores constatan nuevamente la sujeción estética de la narrativa de Abilio Estévez, pero en un grado más complejo, ya que no es sólo la incapacidad de separarse de Cuba, sino que también la incapacidad de dejar vacíos, y por ende, la tendencia a responder, o "rellenar" cada uno de los asuntos inconclusos. Las obras y su exacerbación de material lingüístico y de construcción de imágenes a partir de la reiteración, están bajo el dominio (sujeción) de un otro que aspira a ser dueño absoluto del texto. Ese otro es el narrador totalizador.

Tal como he señalado anteriormente entre sus constantes estilísticas estructurales predomina la intertextualidad, la cual se cristaliza de diferente manera: en citas literales que se insertan y yuxtaponen al texto "madre" (principalmente en Inventario secreto de La Habana), o citas que encabezan los capítulos de las obras a modo de epígrafes (presentes en todas sus obras narrativas). O textos de diversa índole (literarios, cinematográficos, musicales, etc.) pronunciados o evocados por los personajes. De acuerdo a los postulados de Bajtin, vemos dialogismos como un pilar narrativo en las obras de Estévez: "[el texto] está rodeado e impregnado de ideas generales, de puntos de vista y valoraciones y acentos ajenos $[. .$.$] se entrelaza en complejas relaciones, se une a algunos, rechaza a otros, o se$ entrecruza con los demás" (Bajtin, 1989: 94).

En una primera instancia estas relaciones interdiscursivas o intersubjetivas nos conducirían a la idea de que en la narrativa de Estévez, la imagen de Cuba es construida a partir de una multiplicidad. Concepción que se fortalece al estar las obras compuestas de manera polifónica. Los personajes articulan su discurso, manifiestan su forma de ver el mundo y conforman una pluralidad discursiva (Bajtin, 1986). Sin embargo, esto forma parte del montaje del narrador dominador, quien construye una "polifonía narrativa unificada"16 La pluralidad es aparente, los relatos no les pertenecen. Todo se reduce a una cosmovisión, a una voz hegemónica: el narrador impositivo, totalizador que hace que los personajes no sean sujetos de sus discursos sino que en realidad objetos de ellos.

Bajtin indica que el acontecer estético "puede darse únicamente cuando hay dos participantes [autor y personajes], presupone la existencia de dos conciencias que no coinciden" (1986: 28). En las obras de Abilio en realidad no difieren. En un eventual análisiss, sería interesante problematizar las novelas de autor de acuerdo a los postulados de M. Bajtin en torno a la (extra) posición del autor respecto a lo representado y ver si se logra o no lo que ha llamado "acontecer estético."
Este rasgo presente en todas sus obras se explicita denotativamente en Tuyo es el reino y Los palacios distantes al suprimir los signos gráficos que dan paso a los diálogos de los personajes, siendo éstos enunciados o apropiados por la voz del narrador: "Mercedes le pide: No te pongas así. Irene niega con la cabeza y agrega: Cómo me voy a poner si vi a mi propio hijo" (1998: 55); "Y Patria o Muerte, Venceremos, finaliza Salma animada, y de inmediato agrega: Es un amigo mamá, se llama Triunfo" (2002: 53); "Victorio se atreve a preguntar ¿Qué le pasa a Salma? ¿Salma?, pregunta el Negro con desconcierto, ¿quién es Salma?” (2002: 212).

Hemos visto cómo el narrador, bajo la reiteración y autorespuestas, resuelve lo inconcluso y otorga unicidad. Sin embargo, la génesis de esta constante se encuentra en la tendencia a lenguaje acotacional y en la estructuración metaliteraria. Por una parte, y como es propio del texto dramático, se identifican las múltiples notas "marginales", las cuales funcionan de diversas maneras: para advertir sobre algún suceso, "Un personaje cuyo nombre es Irene, ... ahí lo dejamos (por ahora)" (1998: 109); para reflexionar en torno a una idea planteada, "He hablado de las ilusiones que procuraba o procura (¿por qué esta obstinación de hablar en pasado)” (2004: 61), “era, la realidad tal como él suponía (si es que suponía algo a esa hora) que debía ser" (2008: 93); para hacer comentarios paralelos a la narración, "Así, cada vez que ve una pareja de policías (y esto en La Habana del año 2000 sucede a cada minuto, a cada segundo, a cada fracción de segundo) va directo a su encuentro" (2002: 64). También para aclarar el por qué el uso de un léxico, "La explicación de esta fantasía (por usar la fea palabra de moda)" (2008: 231), etc.

Bajo este mecanismo, la narración cae en una performatividad, el narrador continúa delimitando al lector, guiando el imaginario que él está construyendo, como si tuviera el temor de no ser bien comprendido, o más bien, de que su perspectiva no se represente tal cual como él la concibe, impidiendo que el suceso en sí cobre valor. Este hecho también permite explicar, en un nivel más secundario, el excesivo uso de paratextos en las obras de Estévez. Los títulos ya configuran de antemano la significación de los relatos, (siendo quizás Los palacios distantes el que menos anticipe la temática del libro y el que menos paratextos utiliza). A esto se le suma que todos están divididos en capítulos con sus respectivos subtítulos y precedidos de epígrafes que anuncian las temáticas o sucesos narrativos, hasta el punto que estos discursos auxiliares, que en principio están al servicio del texto, terminan siendo una total anticipación lectora, que debido a su redundancia significativa, asfixian y coartan al lector. Por ejemplo, en Tuyo es el reino el cuarto capítulo llamado "Finis gloriae mundi" y su epígrafe "Nunca más brillará en ti la luz de una lámpara" del Apocalipsis, o en Inventario secreto de La Habana en el que no basta con la cantidad de textos intercalados sino que además hay una gran cantidad de notas a pie de páginas. Sin embargo, es en El navegante dormido en el cual este procedimiento está en demasía: subtítulos, epígrafes y además subsubtítulos innecesarios que no aportan a los relatos, sino que más bien cortan la lectura, la interrumpen.

Los epílogos, también presentes en todas las obras, cierran esta condición paratextual de manera totalizadora. Su rol no sólo se destaca por presentar el desenlace o conclusión, sino que funcionan, por una parte, como recapitulación en la que se vuelve a temas y sucesos anteriormente tratados y en ocasiones sintetizan ("expoliativamente") lo narrado, como es el caso del epílogo de El navegante dormido:

Valeria se dispondrá a imaginar situaciones y conflictos. Y comenzará a escribir este libro, lo que será la historia de una vieja casa de madera frente al mar, así como la historia de una o varias huidas, de un ciclón y de algunos fantasmas (Estévez, 2008: 365; cursivas de la autora). 
También funcionan como apartados adicionales en los que se explican y resuelven aquellas partes de la historia que no han quedado resueltas. Este es el caso de Los palacios distantes, el cual en su último párrafo explica el por qué del final (motivo que, sin ser verbalizado, ya se había desprendido del texto): "La Habana era la única ciudad del mundo preparada para acogerlos. También parecía la única superviviente de cuatro largos siglos de fracasos, plagas y derrumbes" (2008: 272). Y principalmente, de Tuyo es el reino, ya que en el epílogo, titulado, "La vida perdurable" el espacio donde el narrador a partir de la reflexión en torno al poder y función del autor-narrador, no sólo relata el final, sino que lo va justificando, contextualizando, explicando lo que es la literatura para él y aclarando quién era el misterioso personaje (alter ego del autor) narrador de la historia narrada, Sebastián: "Tuve a bien repetir para mis adentros los versos del libro aquel robado la tarde en que mi madre [Helena] me mandó en busca del Tío" (1998: 324).

Finalmente, y quizás el procedimiento más consagrado del autor y más causante de su estética de la sujeción y expolición, es el recurrir a lo metaliterario, rasgo en el que confluyen y acrecientan todos los aspectos ya analizados. En Tuyo es el reino y en El navegante dormido son las novelas donde el fenómeno de lo metaliterario es el eje de la articulación de las narraciones. Ambas comparten la reflexión de la novela y su construcción, la existencia de un personaje narrador- escritor quien cuenta (Sebastián) o contará (Valeria) la historia. En ambas la página se configura como un soporte que permite manipular el proceso de escritura y lectura, y por tanto, este espacio y relevancia que se le da a la construcción del texto mismo, permite la utilización de recursos que demarcan la lectura, la conducen y explican.

En primer lugar, se aclara que se está frente a una novela/libro, por lo que el límite entre lo ficcional y lo real, está sujeto a ser transgredido: "(nada de esto sucede: nos encontramos en una novela)" (1998: 24), "decidirá contar la historia que se intenta narrar en este libro" (2008: 30). Esta se constituye en una premisa mayor ya que lo escrito se configura como un todo, el todo narrativo, donde cada aspecto puede ser reflexionado, anulado, acentuado, y sobre todo, revelado.

Estos recursos son utilizados para anunciar los sucesos que ocurrirán, o más bien, para potencializar la atmósfera en la que se desenvuelve la trama que ha sido fraccionada cronológicamente, como si se estuviera declarando que el final no es lo más relevante ya que se está condenado a lo mismo:

Como este relato se escribe en Cuba, la lluvia cae con furia [...]. En Cuba el Apocalipsis no sorprende [...]. Razón por la cual este capítulo comienza con un aguacero que presagia el fin sorprende [..... Razon por la cual este

Es justo que esta narración comience con una amenaza puesto que la historia que en ella se Es justo que esta narración comience con una amenaza puesto que la historia que en ella se
relata $[\ldots .$.$] coincide con el momento en que el huracán anunciaba su violencia en las costas$ relata $[\ldots .$.$] coincide con el momento en que el huracán anunciaba su violencia en las costas$
de La Habana $[\ldots]$. El libro se abre no sólo con una fotografía, una casa y un camino, sino, además, con un ciclón (Estévez, 2008: 21-2)

Con este fenómeno, vemos también, cómo se manifiesta nuevamente la expolición, ya que el suceso que en ambas se anticipa es el de la desaparición, de la catástrofe, la extinción. Esto se acentúa en la presentación de los personajes, los cuales se caracterizan bajo una misma condición de desventurados: "estos pobres personajes siguen creyendo que andan dormidos [...] deben experimentar desamparo [...] es lógico si son cubanos [...] desvalidos" (1998: 244-5); "mansos y resignados, los personajes de esta historia se hallan sentados alrededor de la gran mesa de la cocina" (2008: 332).
El procedimiento se completa y complejiza con la constantes apelaciones al lector, lo que en una primera instancia, nos conduce a la idea de que éste es considerado también un personaje, otro agente activo de la escritura: "Si el lector no propone otra cosa, Irene se inclinará" (1998: 38); "nadie debe sorprenderse de que el futuro tirano sanguinario [Fidel Castro], sin escrúpulos (aquí el lector puede agregar todos los tópicos, cuanto adjetivos terribles se le ocurra)" (2004: 163). Sin embargo, y tal como ya he mencionado, el lector es guiado completamente por la lectura, su recorrido está preestablecido, por lo que estas apelaciones hacia él no son en realidad espacios de participación. Es manipulado, engañado y en los cierres de los libros se cansa, ya que el narrador, aún en la última instancia de libertad receptora, continúa situándose como el agente supremo:

Me doy el lujo de hacer una confesión: sólo yo puedo apagar el fuego: sólo yo soy responsable los a los bomber [..] sin saber que mí, sin saber que el milagro no corresponde a Dios sino a mí, que en este caso (sólo en este caso), venimos siendo la misma persona (1998: 319).

Es el fenómeno de lo metaliterario lo que hace que este narrador Dios, omnipresente y omnisciente, termine por ahogar el propio artificio creado por él. El remitir tanto a la escritura, el exceso de acotaciones y adjetivaciones y las innecesarias aclaraciones, terminan siendo procedimientos que ocultan una simulación: en realidad no se pretende que el lector tenga una participación sino que se configure como un silencioso y pasivo espectador, siendo esa la norma que debe regir su lectura.

\section{CONCLUSIONES: AUSENCIA DE LA AUSENCIA COMO SOSTENEDOR DE SU}

\section{ESTÉTICA}

La propuesta literaria narrativa del escritor cubano Abilio Estévez radica en desmantelar a cabalidad el imaginario exotista de Cuba a partir de la utilización de recursos y métodos estilísticos postmodernos. Sin embargo, estos elementos, como la fragmentación tiempo espacial y estructural; la disolución del sujeto y de la identidad cubana; el antiescencialismo, etc. son en realidad aparentes.

Es posible identificar una homogeneidad semántica en las cuatro obras en cuestión, una isotopía de la devastación y por ende, de la amenaza, que marca el tono de los relatos, enclaustrándolos en una atmósfera de pesimismo. De esta forma, se presenta, a nivel retórico, la repetitividad del signo como primera constante de su propuesta literaria.

Por su parte, la estructura es, en realidad, de carácter monológica. Todas las voces presentes, tanto en los personajes como en los intertextos, son apropiadas por el narrador, quien las cristaliza en un "yo" (el "yo" de Sebastián y Valeria junto al "yo" del narrador macro en el caso de Tuyo es el reino y El navegante dormido; y el "yo" del narrador- autor en Inventario secreto de La Habana), y en un anonimato impersonal (como es en Los palacios distantes). De esta manera el narrador se posiciona y desde ahí, desde esa palabra unívoca, ejerce su dominio textual.

Se podría pensar en una disolución identitaria de "lo cubano", sin embargo, con toda la redundancia se conduce a una esencialidad que diluye el paradigma postmoderno. El sujeto no se disgrega tanto, más bien se vuelve a unificar. 
Por tanto, el narrador y los métodos narrativos circunscriben a los relatos en una atmósfera asfixiante, en donde la predominante intención de reforzar y acentuar las ideas termina siendo un patrón que no seduce, sino más bien harta y trunca las expectativas del lector. Una acumulación e improductivo derroche de recursos estilísticos que evidencia el horror al vacío del narrador (y autor), plasmando a sus obras en un barroquismo literario que no da paso a la elipsis.

¿Qué es lo que busca su propuesta literaria?, ¿preservar a Cuba?, ¿alterarla?, ¿redimirla?, ¿parodiar a los referentes?, ¿satirizarlos?, ¿darles voz? Es terminar con la condición fantasmagórica de la isla y sus sujetos, con aquella condición surgida tras la imposición eterna de un silencio, lo que hace que el imperante terror al borramiento total de lo cubano vea en la saturación un medio de perduración y subsistencia.

\section{REFERENCIAS:}

Bajtin, Mijail. (1989). "La palabra en la novela”. En Teoría y estética de la novela. Trabajos de investigación. Madrid: Taurus.

-. (1986). Problemas de la poética de Dostoievsky. Buenos Aires: Fondo de Cultura Económica.

Estévez, Abilio. (2008). El navegante dormido. Barcelona: Tusquets.

-. (2004). Inventario secreto de La Habana. Barcelona: Tusquets.

-. (2002). Los palacios distantes. Barcelona: Tusquets.

-. (1998). Tuyo es el reino. Barcelona: Tusquets.

Jameson, Fredric. (1986). "Third-World Literature in the Era of Multinational Capitalism”. En Social Text, n. 15 (otoño): 65-88, publicado por Duke University Press Stable. Obtenido desde: http://www.jstor.org/stable/466493. El 28/11/2008

Kristeva, Julia. (1981). Semiótica 1, Madrid: Fundamentos.

Lejeune, Philippe. (1991). "El pacto autobiográfico.” Ángel Loureiro (ed.). En La autobiografía y sus problemas teóricos. Estudios e investigación documental. Suplemento Anthropos 29. Trad. Ángel G. Loureiro. Barcelona: Anthropos.

Piñera, Virgilio. (1990). "La vida tal cual”. En Unión. Revista de la Unión de escritores y artistas de Cuba. Especial: "Virgilio, tal cual" n. 10, año III, abril-mayo-junio, La Habana. —. (2000). "La isla en peso". En Arrufat, An (comp.) Obra poética. Virgilio Piñera. Barcelona: Tusquets.

Sepúlveda, Magda. (2003). "La construcción de identidades, sus imaginarios y su posición en la literatura”. Santiago. Taller de Letras 32: 67-78.

Zambrano, María. (1948). "Mi Cuba secreta”. En Orígenes 20: 63-69. 